Gut, 1985, 26, 258-266

\title{
Elastosis in diverticular disease of the sigmoid colon
}

\author{
JANET WHITEWAY AND B C MORSON \\ From the Pathology Department, St Mark's Hospital, London
}

SUMmaRY Diverticular disease of the sigmoid colon is an increasingly common clinical problem in the ageing population of western industrialised countries but the mechanism by which the disease develops remains unknown. The muscular abnormality is the most striking and consistent feature and this has been studied by light and electron microscopy in 25 surgical specimens of uncomplicated diverticular disease and in 25 controls. This is the first ultrastructural study of human colonic muscle to be published and shows that the muscle cells in diverticular disease are normal; neither hypertrophy nor hyperplasia is present. There is, however, an increase in the elastin content of the taeniae coli by greater than $200 \%$ compared with controls: elastin is laid down between the muscle cells and the normal fascicular pattern of the taeniae coli is distorted. There is no alteration in the elastin content of the circular muscle. As elastin is laid down in a contracted form, this elastosis may be responsible for the shortening or 'contracture' of the taeniae which in turn leads to the characteristic concertina-like corrugation of the circular muscle. Such a structural change could explain the altered behaviour of the colon wall in diverticular disease and its failure to change on treatment with bran.

Diverticular disease of the sigmoid colon is an increasingly common clinical problem in the older age groups of industrialised western countries. ${ }^{1}$ Sixteen thousand Britons and 200000 Americans $^{2} 3$ are annually admitted to hospital for inpatient treatment. Population studies suggest that only $1.3 \%$ of patients with diverticular disease develop symptoms requiring admission and that only $0.5 \%$ ever require operation. ${ }^{+}$These admission statistics therefore represent only the tip of an iceberg encompassing $30 \%$ of the population over the age of 60 and perhaps $60 \%$ of the population over 80.5

The complications of diverticular disease - that is, abscess formation, perforation, fistula, obstruction, and haemorrhage - are well recognised ${ }^{6}$ but the mechanism by which the disease develops, its aetiology and pathogenesis, remain unknown.?

The muscular abnormality ${ }^{8}$ is the most striking and consistent feature in diverticular disease of the sigmoid colon both in surgical specimens ${ }^{9}$ and at necropsy. ${ }^{10}$ The increase in thickening of both the circular muscle layer and the longitudinal taeniae coli, which was first described by Sir Arthur Keith in $1910^{11}$ produces the characteristic concertina-like

Address for correspondence: Dr B C Morson. Consultant Pathologist Department of Pathology. St Mark's Hospital. City Road, London EC1 Received for publication 1 June 1984 abnormality that is a diagnostic sign in barium enema radiographs. ${ }^{12}$ Neither hypertrophy nor hyperplasia of the muscle cells, however, has ever been convincingly demonstrated ${ }^{13} 14$ and the cause of the muscle abnormality remains obscure. It is known that the thickness of the colon wall increases with age, as does the amount of elastic tissue within it. ${ }^{15}$ As diverticular disease also increases with age ${ }^{16}$ a possible role for elastin in the pathogenesis of the condition has been investigated.

\section{Methods}

PATIENTS

The muscle and its connective tissue architecture were studied by light and electron microscopy in 25 surgical specimens of sigmoid colon removed from patients undergoing surgery for 'painful' diverticular disease. (They had no history of any of the complications of the condition but the diagnosis was confirmed by barium enema radiography.) These specimens were received fresh immediately after resection and subsequent examination confirmed the absence of pericolic abscess, inflammation or fibrosis.

The control group was composed of 25 specimens of normal sigmoid colon removed during operation for small non-obstructing rectal neoplasms: 
specimens were excluded if there was radiological or macroscopic evidence of concomitant diverticular disease. The patients in this group were age and sex matched with those in the experimental group.

For light microscopy, the specimens were opened along the antimesenteric border and pinned flat on a cork board before fixation in buffered formalin. Tissue was then taken from the mesenteric and both the antimesenteric taeniae as well as the circular muscle at $5 \mathrm{~cm}$ intervals along each specimen (a minimum of 12 blocks per specimen); serial sections were cut from each block and stained with haematoxylin and eosin, van Gieson's stain for collagen and Victoria blue in a modification of Weigert's method (this is highly specific for elastin fibres). ${ }^{17} \mathrm{~A}$ minimum of 12 sections per block were examined.

Transverse segments of colon $5.0 \mathrm{~cm}$ long were taken for electron microscopy at $5 \mathrm{~cm}$ intervals along the length of each fresh specimen (alternating with the material used for light microscopy). These segments were kept intact and distended with $4 \%$ glutaraldehyde with $0.1 \%$ sodium cacodylate buffer and an added physiological concentration of calcium ions at $\mathrm{pH} \mathrm{7.4}$. The distended segments were then submerged in the same fixative and fixed for 18 hours. ${ }^{18}$ The colon segments were then diced to 1 cubic millimetre cubes and post-osmicated in buffered Osmium tetroxide. Thin sections were then cut and stained with lead citrate and uranyl acetate. ${ }^{19}$ In order to examine the elastin in more detail, some sections were stained with Ruthenium red ${ }^{20}$ Hundreds of sections from each area were studied and randomly photographed using an Hitachi HS9 electron microscope.

Elastic fibres were quantified using a morphometric method developed by Niewoehner and Kleinerman: ${ }^{21}$ the number of coarse and fine elastin fibres per high power field (representing an area of $0.05222 \mathrm{~cm}^{2}$ ) were counted. Counts were repeated blind after six months to ensure reproducibility of results. Morphometric studies of muscle cells were carried out on randomly selected fields using high power electron micrographs at magnifications of $2000 \times$ and $3000 \times{ }^{22}$ Measurements were made directly or using Hewlett-Packard image analysis equipment.

\section{Results}

LIGHT MICROSCOPE APPEARANCES: NORMAL SIGMOID COLON

The circular muscle layer is not homogeneous but is made up of discrete crescentic arcs or bands, each composed of fasciculi 50-200 microns wide, incompletely separated from each other by connective tissue septa. Groups of muscle cells run obliquely between the fasciculi, linking them together. Within the fasciculi, the cells are closely packed in a regular parallel array; they are embedded in a proteoglycan matrix that also contains collagen and elastin fibres.

Collagen fibres are abundant, surrounding each cell and running parallel to them; they are also condensed into bundles between fasciculi. Elastin is much more sparsely distributed with coarse fibres concentrated around the myenteric plexus and between the fasciculi (Figs. 1 and 3). These fibres form a widely spaced meshwork, running diagonally through the substance of the muscle layer. Larger spaces in the interfibrillary matrix contain capillaries, nerve fibres and interstitial cells.

The longitudinal muscle forms a continuous coat, with three thick taeniae separated by a very much thinner intertaenial zone. The taeniae are also composed of fasciculi: their substructure is similar to that in the circular layer but there is a greater amount of collagen and elastin between the fasciculi. The circular and longitudinal layers are bound together by groups of muscle cells running from the taeniae into the circular layer, accompanied by collagen and elastin fibres, but particularly the latter.

SIGMOID COLON IN DIVERTICULAR DISEASE

In diverticular disease there is prominent thickening of both the circular layer and the taeniae coli. The taeniae are almost cartilaginous in texture and, macroscopically, the fasciculi are individually more prominent.

In the circular muscle, there is exaggeration of the crescentic bands and their fascicular pattern: the fasciculi are attenuated and their width reduced to 10-50 microns. The increase in thickness may be even or may occur in irregular bands, giving a 'wavey' appearance to the submucosal edge of the muscle; the thickness is further increased by the folding up of adjacent areas of muscle upon themselves.

The taeniae show only a uniform increase in thickness with none of the variations seen in the circular layer. In neither muscle layer is there evidence of contraction - shortened, fatter nuclear profiles, folded cell margins or increased intensity of staining.

Light microscopy reveals an obvious increase in the content of both coarse and fine elastin fibres in the taeniae coli (Fig. 2). The normal fascicular pattern is distorted and a much denser meshwork of fibres runs through the muscle cells (Fig. 4) resulting in a mosaic appearance in transverse section as individual cells are outlined by elastin. The amount 

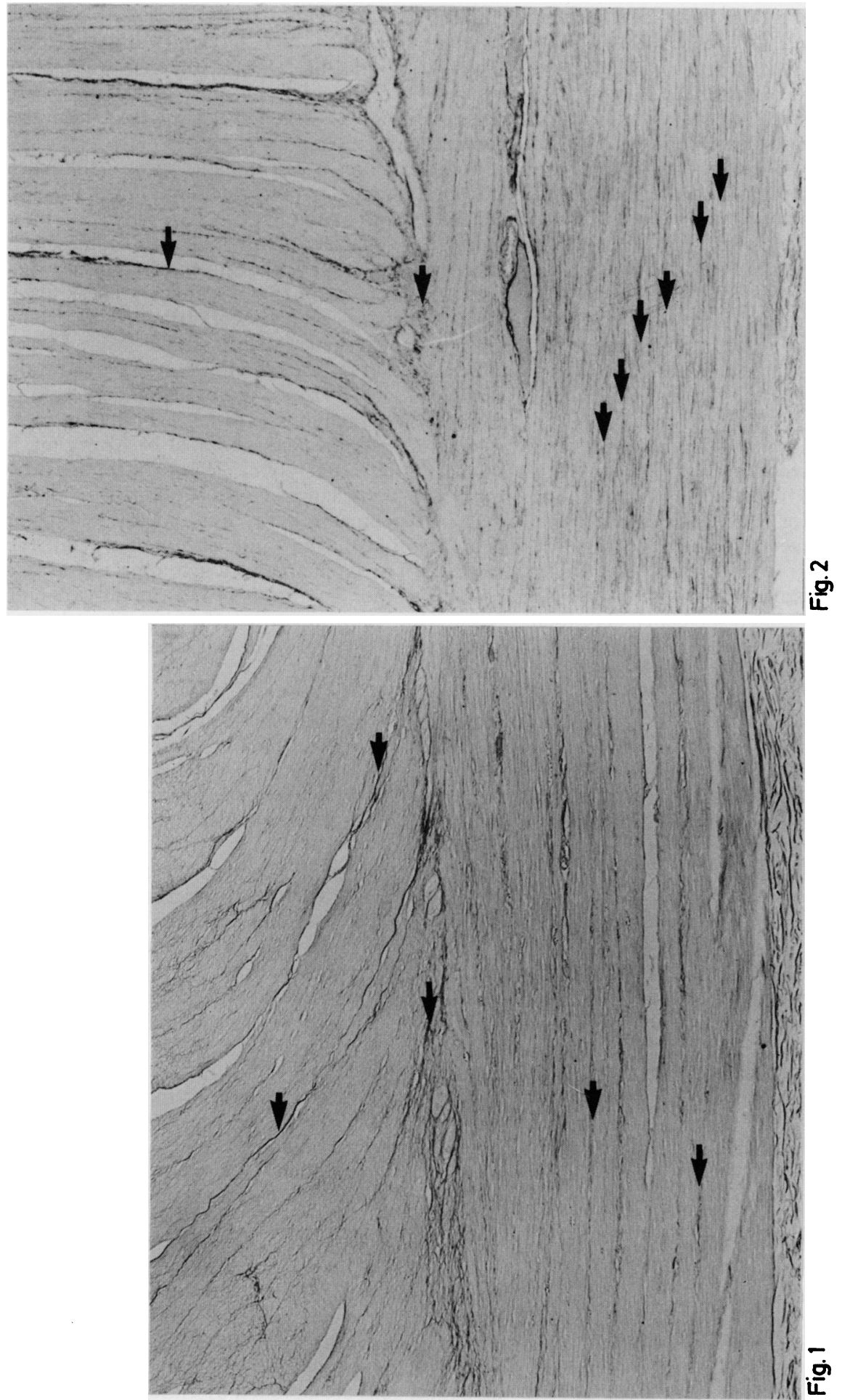

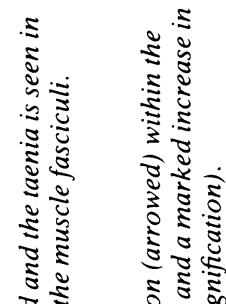

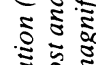

ษั

竎.

ฐะี

ฟิ

플

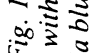

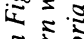

इ

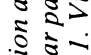

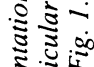

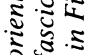

है ป

究

วิธ

ङั

政

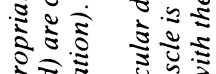

रำ

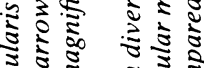

도ำ

施方

造

을

5.

ㅎํㅇำ

혼ำ

ำ

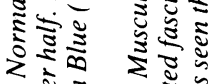

ำ

นิ 


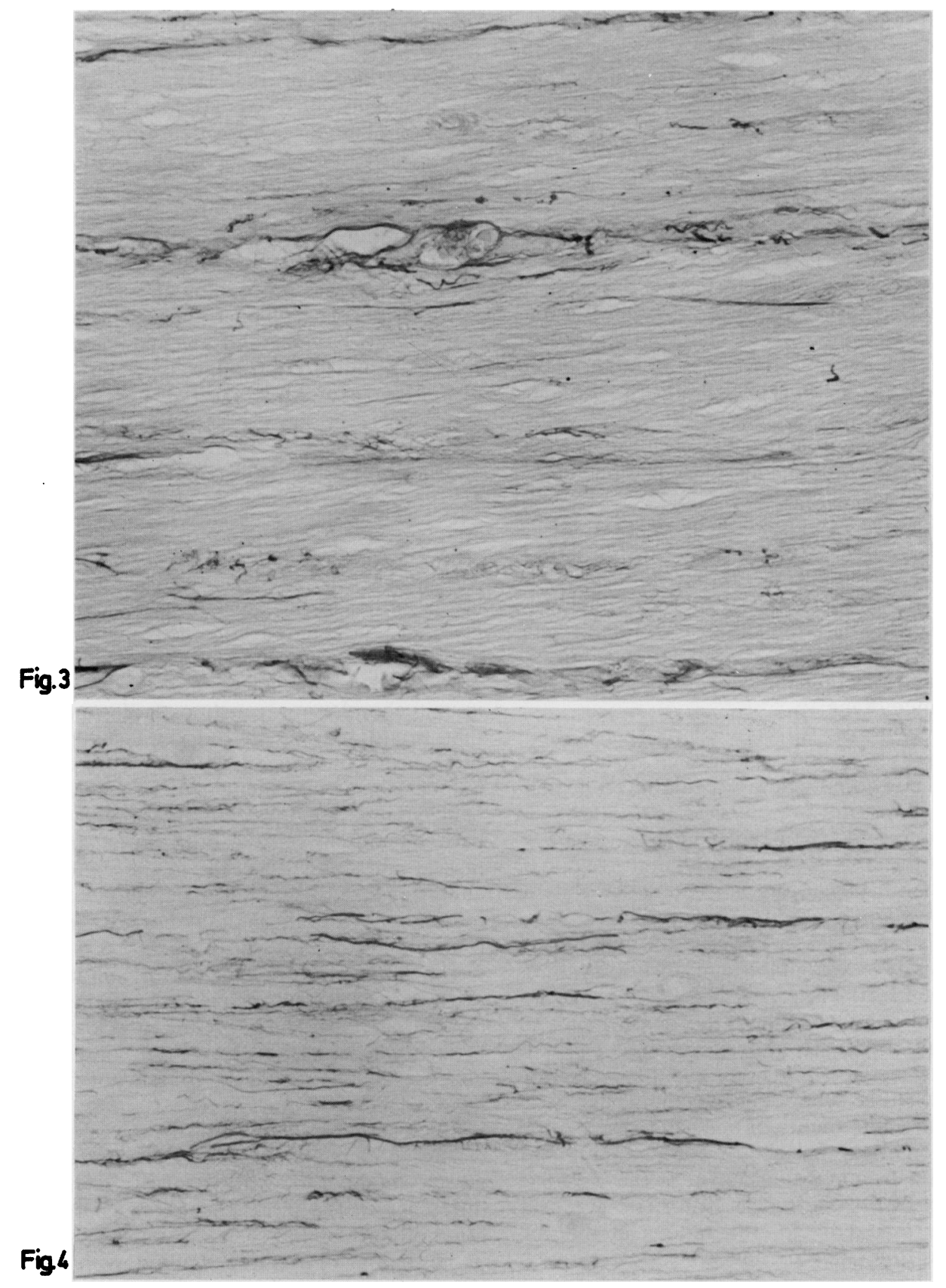

Fig. 3 High power view of normal taenia. Elastin is concentrated between the muscle fasciculi and little elastin is seen between muscle cells. Victoria blue $(\times 225$ original magnification $)$.

Fig. 4 High power view of taenia in diverticular disease. The normal fascicular pattern is lost and there is a considerable increase of both coarse and fine elastin fibres compared with Fig. 3. Victoria blue $(\times 225$ original magnification $)$. 
of elastin around the fasciculi is also increased.

The amount and distribution of elastin in the circular muscle is not increased. The appearance and amount of collagen is normal in both muscle layers. There is no change in the ratio of muscle cells to matrix but there is more elastin within the latter.

ELECTRON MICROSCOPE APPEARANCES: NORMAL SIGMOID COLON

The muscle cells are of uniform size and spindle shape; because of their small size they have a high sarface-to-volume ratio. The ellipsoid nuclei are centrally placed and nucleoli are seen in about 5\% of nucleated cells. Within the cell mitochondria and elements of smooth endoplasmic reticulum lie close to the cell membrane and near the nuclear poles. Smaller amounts of rough endoplasmic reticulum lie within the cytoplasm (Fig. 5).

The cell surface is modified by several special structures. Rows of caveolae (spheroidal invaginations of the cell membrane with a narrow opening to the extracellular space) alternate with dense bands which are the site of insertion of actin filaments. Both are arranged parallel to the long axis of the cell and together they cover the greater part of the cell membrane.

Gap junctions of two types are seen: either slightly raised from the cell surface or on short processes. They do not show a regular arrangement along the cell but are present in equal numbers in both the taeniae and the circular muscle.

Mainly at the ends of the cells and in the region of the dense bands, anchoring fibrils link the cells to the collagen component of the interfibrillary matrix. Elastin is also seen closely apposed to some muscle cells but this is less common and anchoring fibrils could not be identified.

Within the muscle bundles, the dense bands of adjacent cells often lie opposite to one another, forming intermediate junctions and here electron dense material is seen between the cells. Such junctions often link the tip of one cell to the central part of a neighbouring cell. In contraction, these bands remain in apposition and it is the caveolae bearing part of the cell that is distorted. The cells can also be linked by interdigitations in the cell membrane at the tapered ends.

Collagen fibres are readily identified by their characteristic cross-striations: the period length in this study was $45-50 \mathrm{~nm}$. The fibres themselves are uniform in size, about $35 \mathrm{~mm}$ in diameter. They run singly between the cells and, as a result of their insertion into the dense bands, link the muscle cells both to the matrix and to one another (Fig. 5).

Elastin fibres have two components: a central amorphous core of the protein elastin makes up the major part of each mature fibre and is surrounded by fine beaded filaments. ${ }^{23}$ During elastogenesis, the electron dense filaments are laid down first and act as a template for elastin deposition. ${ }^{24}$ Newly laid down elastin is electron dense, becoming lucent as it matures. ${ }^{25}$ Most of the elastin in both muscle layers was electron lucent and therefore mature, but a little darker staining material was seen. Only rarely were fine filaments seen in isolation, suggesting that elastogenesis was proceeding at a slow rate.

Under the electron microscope, elastin fibres have a wavey appearance and are mainly seen between muscle bundles confirming the light microscope appearances. They run longitudinally and transversely in the same plane thus forming the diagonal meshwork. No structural attachment of elastin fibres to the cells could be made out.

\section{SIGMOID COLON IN DIVERTICULAR DISEASE}

The muscle cells are of uniform size in both muscle layers: although the fasciculi in the circular muscle layer are attenuated, the cells within them are arranged in an identical manner. The complement of organelles is unchanged and there is no increase in mitochondria or rough endoplasmic reticulum that would suggest altered cell activity. The cell profiles are unchanged with no difference in the numbers or arrangement of the caveolae or dense bands. Gap junctions and intermediate junctions between muscle cells in both layers and between muscle and interstitial cells in the taeniae are not altered in size or number. The muscle cells appear no different from those in the normal sigmoid colon (Fig. 6).

The collagen content and organisation is not altered in either muscle layer: this provides corroborative evidence that the muscle cells are not hypertrophic as such a change is accompanied by an increase in the collagen content of the muscle involved.

Electron microscopy confirms the increase in the elastin content of the taeniae but not the circular muscle compared with controls. There is no difference in the ultrastructure of coarse and fine fibres other than that of size. A much greater variety in the staining of elastin was noted, with some fibres staining darkly, suggesting recent deposition. Isolated groups of fine filaments were seen lying alone in the matrix: this suggests active elastogenesis. In some areas, especially near the neurovascular bundles, where a greater amount of elastin is concentrated, the elastin had an almost lamellar appearance like that seen in the elastic lamina of small arteries. 


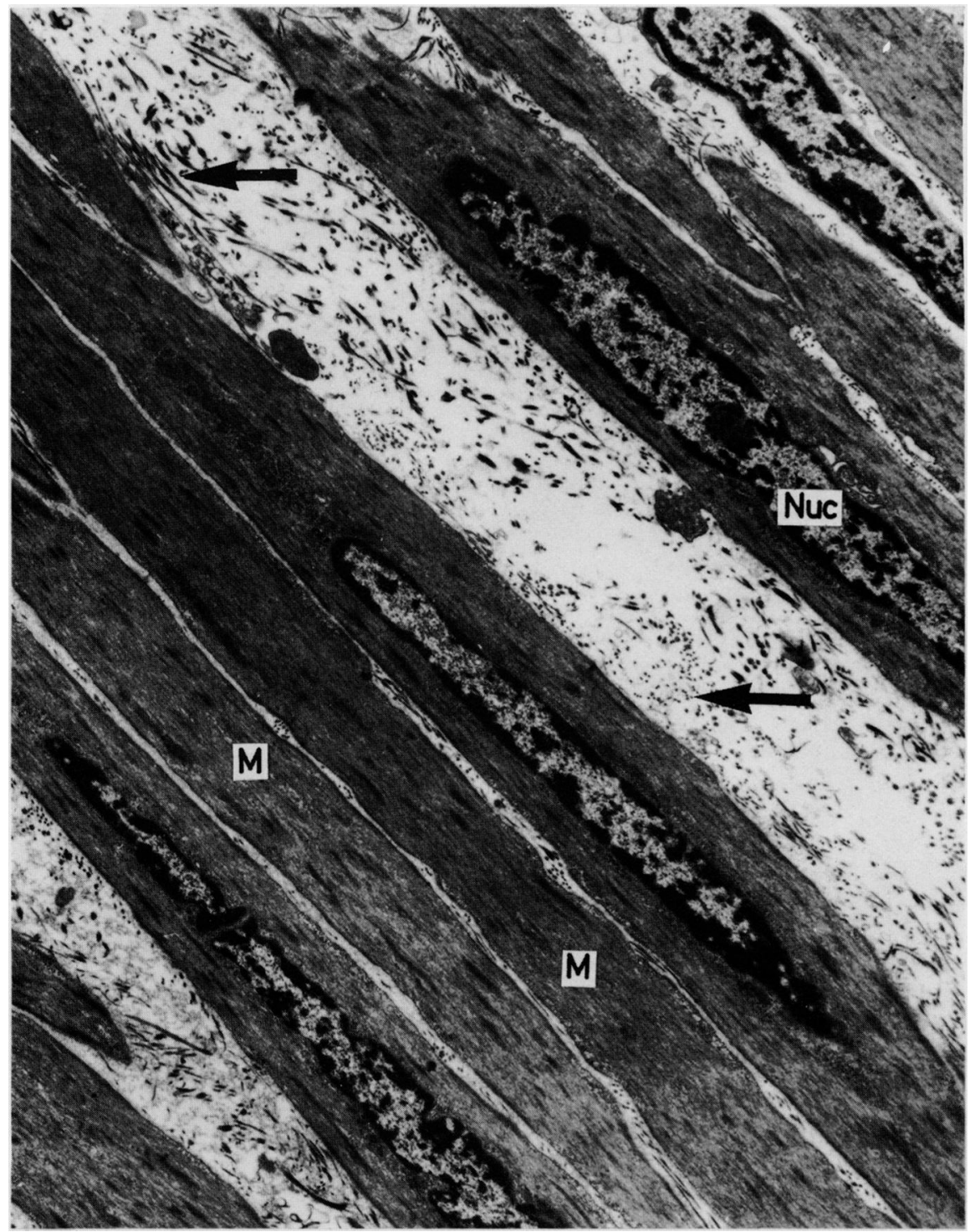

Fig 5

Fig. 5 Normal taenia with collagen (arrowed) seen between normal muscle cells $(M)$. There are no elastin fibres between the muscle cells. $(\times 7500$ original magnification $)$.

\section{MORPHOMETRY}

Muscle cell lengths were computed from measurements of nuclear length and the percentage of nucleated cells:22 cells in the circular muscle and taeniae of control specimens measured $640 \mu \mathrm{m}$ and $605 \mu \mathrm{m}$ respectively; cells in the circular muscle and taeniae in diverticular disease measuring $625 \mu \mathrm{m}$ and $585 \mu \mathrm{m}$ respectively: there was no statistically significant difference between these measurements at the one per cent level (Table 1). Caveolae were of identical size in all types of muscle: $80 \mathrm{~nm}$ wide and $110 \mathrm{~nm}$ in length. Dense bands were also of identical size in all types of muscle: $40 \mathrm{~nm}$ wide and $200 \mathrm{~nm}$ in length. It was impossible to measure gap junctions accurately without freeze fracture techniques but there appeared to be no difference in size in the 
different types of muscle.

Elastin was quantified by high power light microscopy: the increase in elastin in normal taeniae compared to circular muscle seen subjectively was confirmed. There was no difference in the number of coarse or fine fibres in the circular muscle in diverticular disease compared with controls but there was a highly significant difference between the amount of both coarse and fine fibres in the taeniae of the two groups (Table 2). The elastin content of the taeniae in diverticular disease was increased by at least $200 \%$ compared with controls.

\section{Discussion}

This study has shown that although the circular 
Table 1 Muscle cell length $(\mu \mathrm{m})$

\begin{tabular}{lll}
\hline & Diverticular disease & Control \\
\hline Circular muscle & 625 & 640 \\
Taeniae coli & 585 & 605 \\
\hline
\end{tabular}

Student's $t$ test; p NS.

muscle layer and the taeniae coli are thickened the reason for the thickening differs in each layer. The taenia are thicker as a result of the contracture secondary to elastin deposition; the circular muscle is thicker as a result of the lengthwise compression and muscle folding caused by the shortening of the taeniae. The muscle cells are normal in both layers. Can this elastosis of the taeniae coli explain the anatomical and functional changes seen in this condition?

The advantage of access to specimens of uncomplicated diverticular disease meant that any change that was observed was not a response to inflammation, fibrosis, or obstruction. The muscle thickening takes place at an early stage in the disease: the pattern of the circular muscle bands is similar to that seen in a necropsy study which concluded that the thickened taeniae showed no demonstrable abnormality. ${ }^{10}$ Light microscope sections of the taeniae stained with haematoxylin and eosin in this study also showed no abnormality but prominent elastosis was observed using a special stain for elastin.

Muscle cell hypertrophy has been reported in one morphometric study but most of the specimens studied were complicated by inflammation, some extensively, and different specimens were fixed under different conditions. ${ }^{14}$ Our morphometric measurements have shown no evidence of hypertrophy - that is, cells with a greater cytoplasm-tonucleus ratio, invaginated membrane or increased intercellular collagen. There is also no evidence of hyperplasia - that is, increased packing density of cells or increased mitotic figures. Equally important, there was no electron microscopic evidence of sustained contraction in either muscle layer

Table 2 Elastic fibres

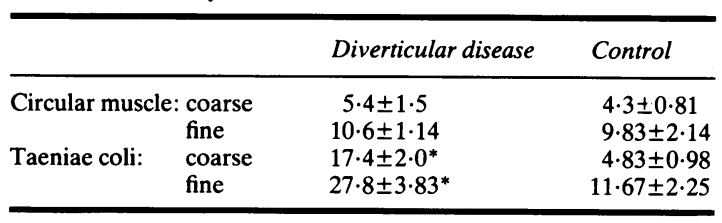

Student's $t$ test $\pm \mathrm{SD} ;{ }^{*} \mathrm{p}<0 \cdot 01 \pm \mathrm{SD}$. although such contraction has been considered important in the pathogenesis of the muscle thickening. ${ }^{26}$

The elastosis is confined to the taeniae where increased elastin is seen both around individual muscle cells and the fasciculi (Fig. 1-4). This pattern of elastosis is important as otherwide any increase of elastin might be assumed to be spurious.

In the presence of normal muscle cells it would appear that the elastosis within the taeniae is the primary change in diverticular disease. This explains the macroscopic and microscopic appearances in the following way. The taeniae shorten the sigmoid colon by about one sixth normally and they act as cables against which the circular muscle can contract. If the taeniae shorten further, they increase the thickness of the circular layer without any change in the morphology or physiology of that layer itself. As shortening proceeds, the thickness increases and eventually the circular muscle folds up on itself to produce the characteristic concertina-like folds.

Elastin molecules take the form of beta helical spirals and they are laid down in a contracted state ${ }^{27}$ thus maintaining the taeniae in a shortened position. An increase in the amount of elastin in the taeniae would therefore increase the distensibility of the bowel wall, as is the case in diverticular disease. ${ }^{28} \mathrm{~A}$ structural change of this sort could also explain why treatment with bran fails to alter the tone and strength of the bowel wall. ${ }^{29}$

The crescentic folds of the circular muscle are much more prominent and much closer to one another in diverticular disease and it is easy to see that when the circular muscle contracts, isolated segments of high pressure, as described by Painter, ${ }^{30}$ can be formed. Increased intraluminal pressure stimulates further elastin production and the elastosis of the taeniae comes to resemble that seen in the wall of the pulmonary artery in pulmonary hypertension. ${ }^{31}$

The initiating factor in the aetiology of elastosis could be the small stools produced on a 'western' diet which only intermittently distend the colon. Such intermittent distension of smooth muscle triggers an increased uptake of matrix constituents (particularly proline) at other sites. ${ }^{32}$ Such a change is independent of alterations in motility and this could correlate with studies showing a normal motility index in asymptomatic patients. ${ }^{33}$

The muscular thickening in uncomplicated diverticular disease can therefore be explained in terms of elastosis and contracture of the taeniae coli in the presence of normal muscle cells. This does not exclude the possibility that hypertrophy or hyperplasia of muscle cells and further elastosis may 
develop in response to subsequent pericolic inflammation and fibrosis.

We thank the St Mark's Research Foundation for a Research Fellowship granted to Miss J E Whiteway, Mr Lloyd Soodeen, and Mrs Juliet Pettit for their expert technical assistance, $\mathrm{Mr} \mathrm{W}$ Brackenbury for light microscope photomicrography and Mrs Maysuri Patani for secretarial work.

\section{References}

1 Painter NS, Burkitt DP. Diverticular disease of the sigmoid colon, a 20th century problem. Clin Gastroenterol 1975; 4: 3-21.

2 Office of Population, Censuses and Surveys. Hospital In Patient Enquiry 1980 (main tables). London: HMSO, 1982.

3 Report to the congress of the US of the National Commission on Digestive Disease, vol 4 Bethesda: Md US Department of Health, Education and Welfare DHEW Publication No (NIH) 79-1887, 1979.

4 Kyle J, Davidson AI. The changing pattern of hospital admission for diverticular disease of the colon. $\mathrm{Br} J$ Surg 1975; 62: 537-41.

5 Connell AM. Pathogenesis of diverticular disease of the colon. Adv Intern Med 1977; 22: 377-95.

6 Goligher JC. Surgery of the anus, rectum, and colon. London: Bailliere Tindall, 1984.

7 Almy TP, Howell DA. Diverticular disease of the colon. $N$ Engl J Med 1980; 302: 324-31.

8 Morson BC, Dawson IMP. Gastrointestinal pathology. 2nd ed. Oxford: Blackwell Scientific Publications, 1979.

9 Morson BC. The muscle abnormality in diverticular disease of the colon. Proc $R$ Soc Med 1963a; 56: 798-800.

10 Hughes LE. Post-mortem survey of diverticular disease of the colon. Part II The muscular abnormality in the sigmoid colon. Gut 1969; 10: 344-51.

11 Keith A. A demonstration on diverticula of the alimentary tract of congenital or of obscure origin. $\mathrm{Br}$ Med J 1910; 1: 376-80.

12 Williams I. Changing emphasis in diverticular disease of the colon. Br J Radiol 1963; 36: 393-406.

13 Slack WW. Bowel muscle in diverticular muscle. Gut 1966; 7: 668-70.

14 Arfwidsson S. Pathogenesis of multiple diverticula of the sigmoid colon. Acta Chir Scand 1964; suppl 342.
15 Pace JL. A detailed study of the musculature of the human large intestine. London: $\mathrm{PhD}$ Thesis, 1966.

16 Parks TG. Natural history of diverticular disease of the colon. Clin Gastroenterol 1975; 4: 53-69.

17 Pearse AGE. Histochemistry, theoretical and applied. Part I, 4th ed. London: Churchill, 1980.

18 Gabella G. On the musculature of the gastrointestinal tract of the guinea pig. Anat Embryol 1981; 163: 135-56.

19 Gabella G. Hypertrophic smooth muscle. Cell Tissue Res 1979; 201: 63-78.

20 Luft JH. Ruthenium red and violet. I: Chemistry, purification, methods of use for electron microscopy and mechanism of action. Anat Rec 1971 ; 171: 347-68.

21 Niewoehner DE, Kleinerman J. Morphometric study of elastic fibres in normal and emphysematous lungs. Am Rev Resp Dis 1977; 115: 15-21.

22 Gabella G. Quantitative morphological study of smooth muscle cells of the guinea pig taeniae coli. Cell Tissue Res 1976; 170: 161-86.

23 Greenlee TK, Ross R, Hartmann JL. The fine structure of elastin fibres. J Cell Biol 1966; 30: 59-71.

24 Ross R, Klebanoff SJ. The smooth muscle cell. I: in vivo synthesis of connective tissue proteins. J Cell Biol 1971; 50: 159-71.

25 Clearly EG, Cliff WJ. The substructure of elastin. Exp Mol Pathol 1978; 28: 227-46.

26 Hodgson J. Transverse taeniamyotomy for diverticular disease. Dis Colon Rectum 1983; 16: 283-9.

27 Sandberg LB, Soskel NT, Leslie JG. Elastin structure, biosynthesis, and relation to disease states. $N$ Engl $J$ Med 1981; 304: 566-79.

28 Smith AN, Shepherd J, Eastwood MA. Pressure changes after balloon distension of the colon wall in diverticular disease. Gut 1981; 22: 841-4.

29 Smith AN, Shepherd J. The strength of the colon wall in diverticular disease. Br J Surg 1976; 63: 666A.

30 Painter NS, Truelove SC, Ardran GM, Tuckey M. Segmentation and localisation of intraluminal pressures in the human colon with special reference to the pathogenesis of colonic diverticula. Gastroenterology 1965; 49: 169-77.

31 Dunnill MS. Pulmonary pathology. London: Churchill, 1982.

32 Leung DYM, Glagov S, Mathews MB. Cyclic stretching stimulates synthesis of matrix components by arterial smooth muscle cells in vitro. Science 1976; 191: 475-7.

33 Weinreich J, Anderson D. Intraluminal pressure in the sigmoid colon. II. Patients with sigmoid diverticula and related conditions. Scand J Gastroenterol 1976; 11: 581-6. 